\title{
Information Technology Issues
}

in China

Jie Yu, Yue Guo, and Prashant Palvia

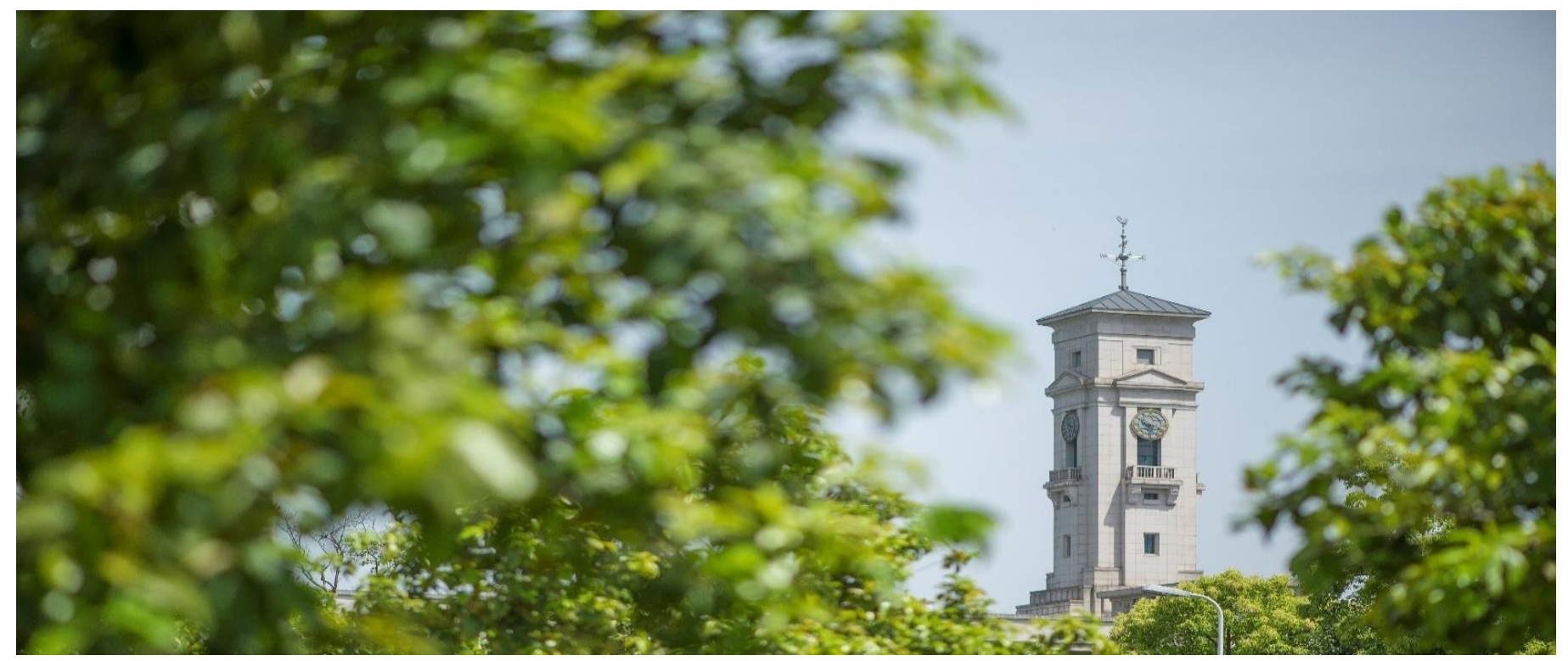


University of Nottingham Ningbo China, 199 Taikang East Road, Ningbo, 315100, China

First published 2020

This work is made available under the terms of the Creative Commons Attribution 4.0 International License:

http://creativecommons.org/licenses/by/4.0

The work is licenced to the University of Nottingham Ningbo China under the Global University Publication Licence:

https://www.nottingham.edu.cn/en/library/documents/researchsupport/global-university-publications-licence.pdf Nottingham 


\title{
Chapter 6
}

\section{Information Technology Issues in China}

\author{
Jie $\mathrm{Yu}^{*, \S}$, Yue Guo ${ }^{\dagger, \uparrow}$ and Prashant Palvia ${ }^{\ddagger}, \|$ \\ ${ }^{*}$ University of Nottingham Ningbo China, \\ Yinzhou Qu, Ningbo Shi, Zhejiang Sheng 315105, China \\ ${ }^{\dagger}$ King's College London, Strand, London, WC2R 2LS, UK \\ $\ddagger$ University of North Carolina at Greensboro, \\ 1400 Spring Garden St, Greensboro, NC 27412, USA \\ §joseph.yu@nottingham.edu.cn \\ 『yue.guo@kcl.ac.uk \\ "pcpalvia@uncg.edu
}

\section{Summary}

In this chapter, we provide important information technology (IT) issues in China, such as organizational IT issues, technology issues, and individual issues. In the World IT Project survey, we recruited 310 IT workers in China. Most of the respondents were in their early career and worked full time in China's IT organizations. The findings show that the most important IT-related organizational issues are: IT reliability and efficiency, security and privacy, and IT strategic planning. Among technology issues, IT professionals identified the following issues as the top concerns: networks/telecommunications, big data systems, data mining, software as a service, and business intelligence/analytics. Most IT employees seem to be satisfied with their current jobs and felt a sense of accomplishment at work. Results further show that more than half of the IT workers would not change their jobs in the short term and felt secure in their current jobs. In addition, there were no significant work-life conflicts among the surveyed IT employees. 


\subsection{Introduction}

Information technology (IT) is advancing rapidly worldwide. The development of IT plays an important role in the economic and social development of nations. On the one hand, IT has positively affected people's lives and has brought significant advantages for business. On the other hand, there are new challenges for IT management and staff. Previous studies have provided IT issues in organizations in some developed countries but there is little literature investigating IT-related issues in China. Since different countries have different economic strategies and market characteristics, IT issues may vary in different countries and regions. Therefore, it seems worthwhile to evaluate the important IT issues in China, such as organizational IT issues, technology issues, and individual issues. The current chapter is designed to provide insights into IT-related issues of Chinese organizations and their IT employees.

\subsection{Country Background and History}

China, officially the People's Republic of China (PRC), is a country located in East Asia with a population of 1.4 billion. China (PRC) was established in 1949 and has reformed the economy and moved forward rapidly from a traditional agricultural society to a modern industrial society since 1978. In the past 40 years, the Chinese government has made every effort to develop its industry and technology. To some extent, China has become an industrialized country with a relatively low level of technology. China has also been investing in high-tech and advanced manufacturing industries in recent years. For example, China has actively accelerated industrialization with informatization and has attained great achievement in the IT industry in recent years, e.g., companies like Alibaba, JD, Tencent, and Xiaomi have emerged. Along with the development of technology, there is increasing growth in China's economy. According to nominal GDP in 2017, China was the world's second-largest economy (Fang et al., 2018).

\subsection{Information Technology in China}

China has gone through an impressive growth in the IT industry over the last two decades. Due to reforms and opening-up policy, China has developed informatization rapidly by allocating considerable resources to the IT industry. In recent years, the IT industry has become one of the pillar 
industries to promote economic development and social progress (Chismar, 1996; Hanna and Qiang, 2011). Over the past 20 years, China has implemented several 5 -year plans to promote the country to be a world-leader and high-tech society through the development of its IT industry.

According to a recent survey, the number of China's Internet users has grown steadily in the last decade and China had 772 million netizens by the end of 2017 (China Internet Network Information Center, 2018). Mobile netizens accounted for $97.5 \%$ of the total Internet users. As of December 2017, the number of Internet companies that had gone public in either domestic stock exchange markets or overseas stock exchange markets has reached 102, with a total market value of RMB 8.97 trillion. There have been 77 Chinese Internet and IT Unicorn Companies 1 The number of artificial intelligence (AI) enterprises has reached 592, accounting for $23.3 \%$ of the AI companies in the world.

In terms of e-commerce, the total retail sales of consumer goods in China was RMB 7.18 trillion, accounting for $40 \%$ of the global online retail sales (China Internet Network Information Center, 2018). Digitization has brought both opportunities and challenges to Internet companies. For example, with advanced information technologies, online payment has quickly replaced traditional payment means of cash, while the issues of online privacy and security have surged.

To conclude, China's IT companies are continuously growing and the IT industry has become the pillar of China's economy. The IT industry is large and complex and important to the world; so it is worthwhile to investigate the IT-related issues in Chinese organizations.

\subsection{Methodology}

The standard English instrument from the World IT Project was translated into Chinese by a research assistant and then the Chinese version was back translated into English by another research assistant for assuring linguistic validity. The back-translation was compared with the original instrument by two researchers. After several discussions, discrepancies were resolved and the Chinese instrument was finalized.

\footnotetext{
${ }^{1}$ Internet and IT Unicorn Companies refer to Internet startups or IT startups valued at more than $\$ 1$ billion each.
} 
Given the length of the survey, early attempts to collect data by hosting the survey on an online service and inviting IT employees from companies were not very successful. Therefore, one of the researchers contacted the MBA/EMBA center from the School of management of a renowned Chinese university. Alumni of this center include many senior executives of various industries in major metropolitan cities of China (e.g., Wuhan, Suzhou, Shenzhen, Jinan, Nanjing, and Guangzhou). The researcher obtained their e-mail addresses from the Center's alumni database. An invitation letter was drafted which explained the objectives and target respondents for the survey. The senior executives were requested to forward the invitation to their IT departments or IT teams. Another researcher contacted an IT professional headhunter company. With their help, every time they contacted a candidate, they invited the candidate to participate in the survey. The data collection started in October 2016 and lasted for about 2 months.

There was no specific incentive or bonus offered to participants. Ethical approval was obtained from the Hohai University Research Ethics Committee. It was presented during the face-to-face interview and was made available if requested by online participants. Communication between the investigators and the core World IT Project team were mainly via emails.

The Chinese sample consisted of 310 IT employees. Nearly all subjects were born in China and $65 \%$ were males. Most of the respondents were relatively young. More specifically, more than half of these subjects (50.3\%) were between 21 and 29 years of age and $31.9 \%$ were between 30 and 39 years of age. The most common job roles were programming (31.9\%), system analysis and design (13.2\%), financial $(7.4 \%)$ and system administrator (7.1\%). The majority of the respondents $(56.1 \%)$ were non-management employees. Detailed statistics are shown in Table 6.1

\subsection{Organizational IT Issues}

Around 18 organizational IT issues were rated by the respondents using a 5-point Likert scale ranging from 1 (of most importance) to 5 (of no importance). Based on the average ratings, the eighteen organizational issues are ranked from 1 to 18 and are shown in Table 6.2]

The findings indicate that IT reliability and efficiency is the most significant IT-related organizational issue. Security and privacy is the second important organizational IT issue, followed by 
Table 6.1: Descriptive Statistics

\begin{tabular}{|c|c|c|c|c|c|}
\hline Characteristics & $N$ & $\%$ & Characteristics & $N$ & $\%$ \\
\hline Education: & & & Years of Work Experience: & & \\
\hline High School or Less & 7 & 2.3 & $0-4$ Years & 126 & 40.6 \\
\hline Associate Degree & 41 & 13.2 & 5-9 Years & 89 & 28.7 \\
\hline Bachelor's Degree & 169 & 54.5 & 10-19 Years & 80 & 25.8 \\
\hline Master's Degree & 83 & 26.8 & 20-29 Years & 10 & 3.2 \\
\hline $\mathrm{PhD}$ & 10 & 3.2 & $30+$ Years & 5 & 1.6 \\
\hline Years of IT Experience: & & & Organizational location: & & \\
\hline 0-4 Years & 162 & 52.3 & IT Department Employee & 212 & 68.4 \\
\hline 5-9 Years & 83 & 26.8 & $\begin{array}{l}\text { IT Worker in Non-IT } \\
\text { Department }\end{array}$ & 43 & 13.9 \\
\hline 10-19 Years & 62 & 20.0 & Contract Employee & 15 & 4.8 \\
\hline 20-29 Years & 2 & 0.6 & Consultant & 34 & 11.0 \\
\hline $30+$ Years & 1 & 0.3 & Vendor Employee & 6 & 1.9 \\
\hline Work as: & & & Work Position: & & \\
\hline Mostly Full Time & 272 & 87.7 & Not Part of Management & 174 & 56.1 \\
\hline Mostly Part Time & 29 & 9.4 & In Lower Management & 59 & 19.0 \\
\hline Mostly Over Time & 9 & 2.9 & In Middle Management & 51 & 16.5 \\
\hline Been Laid Off from IT Job: & & & In Senior Management & 26 & 8.4 \\
\hline Yes & 76 & 24.5 & & & \\
\hline No & 234 & 75.5 & & & \\
\hline
\end{tabular}

IT strategic planning, project management and continuity planning and disaster recovery. Globalization, bring your own computing device (BYOD) and outsourcing are the least important organizational issues in rank.

In the era of informatization, reliable and efficient information technologies are needed to improve employee's work performance and enhance organizations' competitiveness. In China, economic and market reforms have given rise to companies with distinct types of ownership and cultures (Tsui et al., 2006). The complex and nuanced organizational structures may pose challenges to the development of reliable and efficient information systems. Privacy and security are also very important with the booming development of IT and digitization. Privacy and security concerns exist wherever personal sensitive information is collected, used, stored and shared. The era of IT and big data has arrived in China and is contributing in many ways to economic growth. As is the case, a large quantity of data regarding consumers' personal information is a key asset for business firms and other organizations. However, the unauthorized or unintended sharing of such data has led to privacy and security concerns. In recent years, China 
Table 6.2: Organizational IT Issues in China

\begin{tabular}{lccc}
\hline Organizational IT Issues & Rank & Mean Rating* & Std. Deviation \\
\hline IT reliability and efficiency & 1 & 1.98 & 0.84 \\
Security and privacy & 2 & 2.02 & 0.83 \\
IT strategic planning & 3 & 2.04 & 0.86 \\
Project management & 4 & 2.05 & 0.82 \\
Continuity planning and disaster recovery & 5 & 2.09 & 0.84 \\
Alignment between IT and business & 6 & 2.11 & 0.81 \\
Knowledge management & 7 & 2.12 & 0.84 \\
Business productivity and cost reduction & 8 & 2.13 & 0.81 \\
Revenue-generating IT innovations & 9 & 2.14 & 0.79 \\
IT service management (e.g., ITIL) & 10 & 2.15 & 0.85 \\
Attracting and retaining IT professionals & 11 & 2.15 & 0.84 \\
Enterprise architecture & 12 & 2.16 & 0.80 \\
Business agility and speed to market & 13 & 2.17 & 0.85 \\
Business process reengineering & 14 & 2.20 & 0.77 \\
IT cost reduction & 15 & 2.23 & 0.88 \\
Globalization & 16 & 2.25 & 0.89 \\
Outsourcing & 17 & 2.55 & 0.88 \\
BYOD & 18 & 2.61 & 0.93 \\
\hline
\end{tabular}

* Rating scale ranges from 1 to 5 : 1 as most important and 5 as no importance.

has enacted regulations and laws in data privacy and security due to the increasing awareness among people and organizations.

Driven by IT penetration and market-oriented development, IT strategic planning plays an important role in enhancing economic competitiveness in Chinese enterprises. Strategic planning is critical to organizations because it can provide the planners with a road map to get to where they want to be. Strategic planning is also an important tool for motivating a team to work together and make decisions to achieve specific goals via a variety of techniques. It is thus ranked high in our sample.

BYOD, which means employees can bring their own devices to their workplace, is the least important issue in the study. BYOD is an increasing trend in the business world. One survey shows that $75 \%$ of respondents in high growth markets such as Brazil, Russia, India, UAE and Malaysia use their personal device for work, while only $44 \%$ of employees in the more mature markets do so (Drury and Absalom, 2012). In our sample, the participants believe the issue of BYOD is much less important than other priorities. Perhaps in the Chinese culture, employees are happy to accept the flexibility provided by BYOD and do not care about the blurred boundaries between work and their own life. 


\subsection{Technology and Infrastructure Issues}

Once again, the IT employees were asked to rate 16 technology related issues on a 5-point Likert scale ranging from 1 (of most importance) to 5 (of no importance). Results are shown in Table 6.3. The top-five most important issues are networks/telecommunications, big data systems, data mining, software as a service, and business intelligence/analytics.

China's networks and telecommunications have been evolving since the early 1990s and commercial access to the Internet has been available since then (Hanna and Qiang, 2011). With the increasing number of Internet access points and services, networks and telecommunications play a critical role in the development of the Chinese economy. In the context of informatization, networks and telecommunications are important tools for business. Telecommunication-based services can enable companies to communicate effectively with customers and suppliers, and allow employees to collaborate with each other regardless of their location.

Big data systems and data mining are ranked second and third highest. In the data-driven economy, the use of big data has been a vital way for leading corporations to outperform their competitors. Big data and data mining enable companies to analyze massive amounts of data and create

Table 6.3: Technology and Infrastructure Issues in China

\begin{tabular}{lccc}
\hline & & $\begin{array}{c}\text { Mean } \\
\text { IT Related Issues }\end{array}$ & $\begin{array}{c}\text { Std. } \\
\text { Deviation }\end{array}$ \\
\hline Networks/telecommunications & 1 & 2.14 & 0.91 \\
Big data systems & 2 & 2.16 & 0.89 \\
Data mining & 3 & 2.19 & 0.90 \\
Software as a service & 4 & 2.20 & 0.86 \\
Business intelligence/analytics & 5 & 2.22 & 0.84 \\
Customer relationship management (CRM) systems & 6 & 2.23 & 0.87 \\
Cloud computing & 7 & 2.23 & 0.87 \\
Collaborative and workflow tools & 8 & 2.23 & 0.82 \\
Business process management systems & 9 & 2.24 & 0.83 \\
Enterprise resource planning (ERP) systems & 10 & 2.24 & 0.85 \\
Mobile and wireless applications & 11 & 2.24 & 0.88 \\
Service-oriented architecture (SOA) & 12 & 2.25 & 0.86 \\
Mobile apps development & 13 & 2.26 & 0.90 \\
Enterprise application integration & 14 & 2.28 & 0.84 \\
Virtualization (desktop or server) & 15 & 2.28 & 0.86 \\
Social networking/media & 16 & 2.32 & 0.91 \\
\hline
\end{tabular}

* Rating scale ranges from 1 to $5: 1$ as most important and 5 as no importance. 
valuable patterns to help make better decisions. At present, big data and data mining are enormously popular trends in business and research development in China. China's internet companies such as Baidu, Alibaba, and Tencent have collected massive amounts of data and employed the data for their business (Swanson, 2015).

Another important technology in China, ranked fourth, is software as a service (SaaS). SaaS is based on cloud computing and allows software delivery through an internet connection. Employees are able to utilize the software and access the data from anywhere and thus work more effortlessly and efficiently. Given a web browser and internet connection, users can perform their work immediately and do not need to install any software.

With the large amounts of data available to companies, traditional business models are not effective any more. Business intelligence and analytics (ranked fifth) can help decision-makers find revealing insights and make informed decisions. Appropriate analysis supported by business intelligence tools is able to support companies in making a variety of operational and strategic decisions. Chinese organizations have now become aware of the power of business intelligence and analytics, and have put forth great effort to promote the development and use of such tools.

Social networking and media are ranked last in our sample. This is a bit surprising as social networking and media can be considered effective ways to reach potential customers and clients at a very low cost. Weibo and Wechat, which are the two largest social networking platforms in China, seem to have exerted important influence on individual lives. The two applications are also useful tools for branding on social media in China. However, Weibo and Wechat marketing started only a few years ago and may not have directly impacted individual IT employees. In addition, for most Chinese people, social networking sites are thought to be tools to provide individuals with instant message services and entertainment.

\subsection{Individual IT Employee Issues}

Table 6.4 shows the summary of the responses about individual issues. Subjects were asked to rate how much they agree with general statements about individual job issues based on a 5-point Likert scale ranging from 1 (strongly agree) to 5 (strongly disagree). Thus a score below 3 shows agreement with the corresponding item and above 3 shows disagreement. This assessment was made on seven areas of concern and constituted 28 items. The seven 
areas are: job satisfaction, work pressure, work-life balance, workload and burnout, sense of accomplishment, threats to one's job, and career plans.

The percentages of employees who agree or disagree on individual issues are shown in Table 6.5. As can be seen from Tables 6.4 and 6.5. most respondents are satisfied with their current jobs and feel a sense of accomplishment at work. Generally, employees in the IT occupation receive higher pay and enjoy a better work environment than peers in other occupations. In addition, most IT companies provide their employees with better benefits, such

Table 6.4: Individual IT Employee Issues in China

\begin{tabular}{|c|c|c|}
\hline Items & $\begin{array}{c}\text { Mean } \\
\text { Rating* }\end{array}$ & $\begin{array}{l}\text { Std. } \\
\text { Deviation }\end{array}$ \\
\hline \multicolumn{3}{|l|}{ Job Satisfaction } \\
\hline In general, I like working here. & 2.23 & 0.83 \\
\hline All in all, I am satisfied with my current job. & 2.33 & 0.79 \\
\hline In general, I don't like my current job (reversed). & 1.65 & 1.10 \\
\hline \multicolumn{3}{|l|}{ Work Pressure } \\
\hline $\begin{array}{l}\text { I feel that the number of requests, problems or complaints } \\
\text { that I deal with at work is more than expected. }\end{array}$ & 3.02 & 1.07 \\
\hline $\begin{array}{l}\text { I feel that the amount of work I do interferes with how well } \\
\text { it is done. }\end{array}$ & 3.07 & 1.01 \\
\hline I feel busy or rushed at work. & 2.71 & 0.91 \\
\hline I feel pressured at work. & 2.69 & 0.89 \\
\hline \multicolumn{3}{|l|}{ Work-Life Balance } \\
\hline $\begin{array}{l}\text { There is a blurring of boundaries between my job and my } \\
\text { home life. }\end{array}$ & 2.90 & 1.00 \\
\hline $\begin{array}{l}\text { My work-related responsibilities create conflicts with my } \\
\text { home responsibilities. }\end{array}$ & 3.04 & 1.04 \\
\hline $\begin{array}{l}\text { I do not get everything done at home because I find myself } \\
\text { completing job-related work. }\end{array}$ & 3.07 & 1.04 \\
\hline \multicolumn{3}{|l|}{ Workload and Burnout } \\
\hline I feel drained from activities at work. & 3.16 & 0.98 \\
\hline I feel tired from my work activities. & 3.14 & 0.99 \\
\hline Working all day is a strain for me. & 3.20 & 1.01 \\
\hline I feel burned out from my work activities. & 3.27 & 0.97 \\
\hline \multicolumn{3}{|l|}{ Sense of Accomplishment } \\
\hline $\begin{array}{l}\text { I feel I'm making an effective contribution to what this } \\
\text { organization does. }\end{array}$ & 2.32 & 0.85 \\
\hline In my opinion, I do a good job. & 2.31 & 0.85 \\
\hline I have accomplished many worthwhile things in this job. & 2.28 & 0.85 \\
\hline $\begin{array}{l}\text { At my work, I feel confident that I am effective at getting } \\
\text { things done. }\end{array}$ & 2.29 & 0.86 \\
\hline
\end{tabular}


Table 6.4: (Continued)

\begin{tabular}{|c|c|c|}
\hline Items & $\begin{array}{l}\text { Mean } \\
\text { Rating* }\end{array}$ & $\begin{array}{c}\text { Std. } \\
\text { Deviation }\end{array}$ \\
\hline \multicolumn{3}{|l|}{ Threats to One's Job } \\
\hline $\begin{array}{l}\text { I am worried that future technology advancements may pose } \\
\text { a threat to my job. }\end{array}$ & 2.91 & 0.97 \\
\hline $\begin{array}{l}\text { I believe that other people may be able to perform my work } \\
\text { activities. }\end{array}$ & 2.76 & 0.94 \\
\hline I am concerned that my job may be eliminated soon. & 3.09 & 0.99 \\
\hline I am concerned that my job may be outsourced soon. & 3.20 & 1.01 \\
\hline \multicolumn{3}{|l|}{ Career Plans } \\
\hline I will be with this organization 1 year from now. & 2.58 & 0.96 \\
\hline $\begin{array}{l}\text { I will take steps during the next year to secure a job at a } \\
\text { different organization. }\end{array}$ & 3.11 & 0.99 \\
\hline I will be with this organization 5 years from now. & 2.95 & 0.99 \\
\hline I will be working in the IT field 1 year from now. & 2.10 & 0.98 \\
\hline $\begin{array}{l}\text { I will take steps during the next year to secure a job outside } \\
\text { the IT field. }\end{array}$ & 3.50 & 1.09 \\
\hline I will be working in the IT field 5 years from now. & 2.43 & 0.97 \\
\hline
\end{tabular}

* Rating scale ranges from 1 to 5 : 1 as strongly agree, to 5 as strongly disagree.

Table 6.5: Percentages of Employees in Agreement or Disagreement

\begin{tabular}{lccc}
\hline Areas of Concern & $\begin{array}{c}\text { Agree (mean } \\
\text { ratings < 3), \% }\end{array}$ & $\begin{array}{c}\text { Neutral (mean } \\
\text { ratings = 3), \% }\end{array}$ & $\begin{array}{c}\text { Disagree (mean } \\
\text { ratings > 3), \% }\end{array}$ \\
\hline Job Satisfaction & 88.4 & 7.7 & 3.9 \\
Work Pressure & 45.2 & 16.1 & 38.7 \\
Work-Life Balance & 39.7 & 21.6 & 38.7 \\
Workload and Burnout & 31.6 & 17.1 & 51.3 \\
Sense of Accomplishment & 77.7 & 11.3 & 11.0 \\
Threats to One's Job & 33.9 & 30.3 & 35.8 \\
Career Plans & 57.7 & 21.9 & 20.3 \\
\hline
\end{tabular}

as an employee assistant program. They also make a strong effort to further develop employees' skills by providing professional learning opportunities and comprehensive training. Furthermore, IT organizations generally offer employees two pathways for their development; a management development pathway and a professional development pathway. With such an environment and development opportunities, most employees are pleased to work in the IT industry and have a high level of satisfaction. Not only satisfaction, these employees have a high sense of accomplishment and they feel they are doing a good job and making an effective contribution to the organization. 
In terms of work pressure, a moderate number of the respondents $(45.2 \%)$ reported feeling pressured and rushed at work. Chinese companies have to face increased competition and as such, companies may encourage or require employees to work overtime and take responsibilities for unexpected tasks. In terms of work-life balance, the participants did not report significant conflicts. Similar results are found in the area of workload and burnout. Basically, many companies organize a variety of employee recreational activities to help relax their staff and enrich their after-work lives. Some companies even allow employees to work flexibly from anywhere.

The average ratings for threats to job were in the middle and about one-third were concerned, one-third not concerned, and another one-third neutral. On the one hand, IT workers are worried to be replaced due to the increasing number of IT graduates and the rapid development of technologies every year. On the other hand, a large workforce in the IT industry is still needed to promote economic growth and keep IT systems running and growing. There are also a great number of employment opportunities for IT employees and it is easy for a skilled IT worker to find a high-paying job.

The career plans and turnover of IT employees are mirrored by their high levels of satisfaction and accomplishment. A majority (57.7\%) indicated that they would not change their current jobs in the IT field and only $20.3 \%$ were likely to change their career in the near future. Individuals face both challenges and opportunities in the IT field and yet they can choose their own career path if they are talented and competent in information technologies. Generally, most employees in IT companies are satisfied with their jobs for the relatively high salaries and comfortable work environment and do not have plans to change their jobs any time soon. Only a minority may be concerned about unemployment due to fierce competition in the job market.

\subsection{Conclusion}

This chapter presented the organizational, technological and individual issues of IT employees in China. Among IT-related organizational issues, IT reliability and efficiency, security and privacy and IT strategic planning are among the pressing concerns. The top issues in technology included: networks/telecommunications, big data systems, data mining, software as a service, and business intelligence/analytics. The Chinese IT workers seem to be satisfied with their current jobs and had little desire to change jobs. Most of them had a high sense of self-efficacy and sense of accomplishment 
at work. The IT employees believed they had a moderate amount of pressure at work with a healthy work-life balance. In general, these results bode well for the Chinese IT worker.

\section{References}

China Internet Network Information Center (2018). Statistical report on internet development in China. Retrieved from http://www.cnnic.cn/hlwfzyj/hlwx zbg/hlwtjbg/201803/P020180305409870339136.pdf

Chismar, W. G. (1996). Telecommunication and an information infrastructure in China. In Glasson, B. C., Vogel, D. R., Bots, P. W. G., \& Nunamaker, J. F. (Eds.), Information Systems and Technology in the International Office of the Future. Boston, MA: Springer, pp. 91-98.

Drury, A., \& Absalom, R. (2012). BYOD: An emerging market trend in more ways than one. Retrieved from http://www.us.logicalis.com/globalassets/ united-states/whitepapers/logicalisbyodwhitepaperovum.pdf

Fang, C., Garnaut, R., \& Song, L. (2018). 40 years of China's reform and development: How reform captured China's demographic dividend. In Fang, C., Garnaut, R., \& Song, L. (Eds.), China's 40 Years of Reform and Development: 1978-2018. Acton ACT, Australia: ANU Press, pp. 5-26.

Hanna, N. K., \& Qiang, C. Z. W. (2011). China's evolving informatization Strategy. In Hanna, N., \& Knight, P. (Eds.), Seeking Transformation Through Information Technology. New York: Springer, pp. 89-137.

Swanson, A. (2015). How Baidu, Tencent and Alibaba are leading the way in China's big data revolution [South China Morning Post]. Retrieved from https://www.scmp.com/tech/innovation/article/1852141/how-baidu -tencent-and-alibaba-are-leading-way-chinas-big-data

Tsui, A. S., Wang, H., \& Xin, K. (2006). Organizational culture in China: An analysis of culture dimensions and culture types. Management and Organization Review, 2(3), 345-376. 